\title{
A PHOTO VOICE PERSPECTIVE ON FACTORS CONTRIBUTING TO THE RESILIENCE OF HIV POSITIVE YORUBA ADOLESCENT GIRLS IN NIGERIA
}

\author{
Catherine O. Adegoke*, Miemsie G. Steyn \\ Department of Early Childhood Education, Faculty of Education, Groenkloof Campus, University of Pretoria, Corner of \\ George Storrar and Leyds Streets, Pretoria 0001, South Africa \\ *Corresponding author. \\ E-mail addresses: golden2xyz@yahoo.com (C.O. Adegoke), mg.steyn@up.ac.za (M.G. Steyn)
}

\begin{abstract}
There is a growing discourse worldwide on the impact of the Human Immunodeficiency Virus (HIV) on "at risk youths". In response, five HIV-positive Nigerian adolescent girls were qualitatively investigated in collaboration with a non-governmental organisation (NGO) in Ibadan, an urban settlement in Nigeria in 2013. Using a secondary data analysis from a photo voice component of the research, combined with narratives, we show that participants possess the capacity to overcome their adversities from the effects of HIV infection and remain resilient. Few studies have used photovoice - a visual participatory approach - and its impact on this group. The theories of Bourdieu, Piaget and Erikson were used as tools to interpret and document, resilience, social capital and coping among participants. Findings reveal participants frame positive goals, use social competence, coping skills, and express personal challenges. These have serious implications for policy makers, researchers and programmer in strengthening adolescents' resilience.
\end{abstract}

Keywords: HIV; adolescent girl; resilience; culture; social capital; photo voice.

\section{Introduction}

Sub-Saharan Africa is the most heavily affected region in the global HIV epidemic, where 23.5 million people live with HIV/AIDS. This figure represents $69 \%$ of the global HIV burden, while women account for $58 \%$ of the cases (UNAIDS, 2012). The Nigerian data report that people aged between 15 to 24years account for $60 \%$ of infections, while HIV is the leading cause of death and disease among women of reproductive age (15 to 49 years) (NACA, 2011). This indicates that the most affected population is women and girls mostly through heterosexual modes of contact. Growing up with HIV and its' numerous challenges threatens the positive development of the adolescent girl.

Nonetheless not all adolescent girls living with HIV are negatively affected by the various adversities posed by the epidemic. It is believed that many of the girls make concerted efforts to cope with their situation and status, 'thus becoming resilient by living a normal life' (Ungar, 2008). Masten, Best \& Garmezy (1990:425) defined resilience as "the process of, capacity for, or outcome of successful adaptation despite challenging or threatening circumstances". Hence, resilience refers to drawing on past experience, especially one's own experience and from the stock of experiences available in a community or society which includes acting immediately to address such adversities. Henley, McAlpine, Mueller \& Vetter (2010) acknowledged that resilience in street children and adolescents in Tanzania will involve planning, preventing, evading, mitigating, avoiding as well as coping with and reacting to challenging livelihood conditions. A study of resilience among Black South African youth from disadvantaged contexts provided evidence that mandatory services (e.g., education, or foster home placements) only supported youths' constructive adjustment to risk when youths experienced these services as meaningful and respectful (Van Rensburg, Theron, Rothmann, \& Kitching, 2013). Dykes, (2016) reported that resilience develops through an interactive and dynamic process during which an adverse event or circumstances triggers interrelations between protective (such as inner recourses, family and peer networks and community recourses) and risk factors (such as poverty, poor parental and family relations and interactions) that a person may possess or be surrounded with. The protective factors contribute to resilience whereas the risk factors make people vulnerable. The HIV 
epidemic is a risk factor for adolescent girls living with HIV in Nigeria as it rendered them vulnerable to differing psychosocial problems such as discrimination due to stigmatization. Another risk factor or 'threat' of limited choices is poverty which forces adolescents drifting from rural to urban cities for greener pastures. Worldwide, rural-urban drift is known to increase vulnerability to HIV infection (Ajala, 2007). This rural-urban migration, as well as rapid urban development in sub-Saharan Africa, has had a negative impact on adolescent girls - some of whom indulge in sexual promiscuity due to poverty.

The Yoruba culture value formal education which is regarded as an investment and expected to benefit other family members (Adegoke 2015). Hence emphasis is placed on schooling and hard work. Among the Yoruba just like other African cultures adolescence is welcomed with different rituals, feasts or initiation rites while some behaviour is stressed as a mark of transition. For example, Yoruba girls are supposed to be shy and less expressive. Oladepo \& Fayemi (2011) stated that the Yoruba culture through its sustained belief systems in myths concerning premarital sex, time of sexual debut for girls, infertility, and early marriage has resulted in wrong perceptions about HIV/AIDS and subsequently affects its intervention programs. UNICEF (2008) also reports that the adolescent girl in Nigeria is particularly vulnerable and susceptible to HIV infection due to cultural doctrines that promotes male dominance versus female submissiveness. The implication is that even though a woman is married, she does not have any control over her body.

Sex as a topic of discussion is not a norm among the Yoruba people hence; risky sexual behaviour of the adolescent is neither addressed in the community nor in research. Adolescent girls' perceptions of their sexuality and social world or "social space" (Bourdieu, 2004) have barely been explored, due to cultural underpinnings and perceptions. This implies that adolescent girls have been marginalised and their voices hidden within their communities. In this regard Ferreira \& Ebersohn (2012, p. 22) assert that "silence related to HIV and AIDS has often been noted and stigma as well as discrimination has been identified as the primary stressors in HIV and AIDSaffected communities". Another threat to HIV positive Yoruba adolescent girls' development is her fear of being stigmatised. This makes her consequently believes that "life has been permanently altered" (De Santis \& Bassoro, 2011, p. 348). This fear might hinder her from seeking medical care and assistance. In a study of South Africa adolescents orphaned by AIDS, results show that reduction of AIDS-related stigma could potentially reduce adverse psychological outcomes among this population (Cluver, Gargner \& Operario, 2008). It is predicted therefore that research on HIV epidemic will continue to pose numerous challenges, until the coping strategies and resilience of HIV-infected persons are investigated from different paradigms. This article intends to explore how the girls participating in the study have been able to mitigate the negative effects of their experiences of HIV infection and experience resilience through the photo voice technique. The findings of the study are expected to guide programmers, researchers, government organisations and policy makers on how to assist as well as involve HIV positive adolescent girls in Nigeria for social change.

\section{Theoretical frame work}

This study intends to integrate ideas from various theories namely; Piaget (1932/1952), Erikson (1959/68) and Bourdieu (1989/1990) to produce a tool for explaining and predicting the development of participants' behavior and thoughts.

Piaget is perhaps the developmental psychologist best known for his interactional approach and his explanations have focused primarily on the individual. Piaget's theory $(1932,1952)$ conceptualizes development as occurring in stages which according to him plays fundamental roles in shaping children's views of the world around them. Jacob \& Klaczynski (2005) report that Piaget considers adolescence as a stage of life when the ability to engage in higher order reasoning begins to emerge and refers to the commencement of this stage as the formal operational stage starting from age 11 to adulthood. Adolescents at this stage shift from concrete thinking to developing a capacity to think abstractly, engage in logical reasoning, and devise plans to solve problems. They can discern between what is right and wrong behavior and can choose to engage in what is socially acceptable. 
Erikson $(1959,1968)$ is of the opinion that the crucial development of identity occurs in the adolescent phase. He distinguishes three aspects of identity development during adolescence which are:

- $\quad$ The ego identity (self);

- Personal identity (the personal habits that distinguish a person from another;

- Social/cultural identity (the collection of social roles a person plays in the society).

Adolescents' key developmental goal is to develop and integrate these roles into a logical whole by exploring possible ways of putting them together as possible selves in order to mould a personal identity (Arnett, 2000). The concepts of culture, self-esteem and self-concept are also incorporated in the identity formation of the adolescent.

Bourdieu $(1989,1990)$ believes that social reality (the way in which we behave and what we believe to be acceptable) is constructed and determined by those in a high hierarchy of power who force or impose themselves upon agents (the dominated) in the field. For example, society and more specifically the cultures of sub-Saharan Africa, perceive sexuality in young people as a "problem to be managed rather than a positive part of youthful identity" (Aggleton, Ball \& Mane, 2000). Bourdieu's concepts such as agents, field and capitals are also useful to this study. It is conceptualised that adolescent girls' resilience may be influenced by the volume of capital, especially 'social capital' (Bourdieu, 2004) or energy and driving force within their social world, which Bourdieu refers to as the "field". A field refers to a social space in which agents are positioned in definite roles and relationships (Bourdieu, 1990). Likewise the individual HIV-positive Yoruba adolescent girl as an agent is an active member of her field; this is the association of people living with HIV, which is an avenue for social contact and group inclusion necessary for resilient behaviour to develop.

\subsection{Current study}

The first author has a premonition that there exists little knowledge about HIV-positive adolescent girls as a high risk group in Nigeria, while their resilience remains unnoticed. There is also a dearth of research in the field of resilience among Yoruba adolescent girls living with HIV, specifically using participatory visual methods such as photovoice. The research questions that guided the study therefore are: What is the photovoice perspectives of HIVpositive adolescent girls regarding their resilience despite their experiences of the trauma and stigmatisation associated with the disease? How do these photographs express their quest for resilience as well as identify the manifestations of hope in their daily hardships within their community? Answering the above questions is vital given recurrent calls in the resilience literature for researchers and policy makers to guard against researcherdirected explanations of resilience processes that adopt common traits, and that neglect the lived experiences of youths/community members (Liebenberg \& Ungar, 2009; Masten, 2014; Masten \& Wright, 2010; Ungar, 2011a,) . Exploring the experiences of Yoruba adolescent girls living with HIV using the photovoice perspective with narratives addresses these limitations.

\section{Method}

\subsection{Study setting, design and participants}

To answer the above questions, the authors re-examined an existing narrative data set from a qualitative multiple case study which includes a photo voice component with narratives that was generated by 5 resilient, Yoruba adolescent girls living with HIV. The study was carried out in the metropolitan area of Ibadan city the capital of OYO state Nigeria. Ibadan is a typical Yoruba indigenous city with over 3 million inhabitants (NPC (2006) -. The study site is named NECAIN (NELA, Consortium AIDS Initiates in Nigeria), which falls under the initiatives of the Network on Ethics/Human Rights Law, HIV/AIDS prevention, support and care. The previous study followed Wang and Burris's (1997) photo voice nine-step strategy for mobilising community action. The photovoice technique coupled with narratives is a participatory action research that enables participants to define for themselves and others, including policy makers, what is worth remembering and what needs to be changed (Wang, 2006). Recent

photovoice researchers such as Olivier, Wood \& De Lange (2009), as well as Kamper \& Steyn (2011) assert that by using photovoice the researcher has the opportunity of obtaining the most favourable participant involvement, 
dedication and commitment, together with effective capturing of the meanings attached to the photographs. The authors' institution provided ethical clearance for the generation of the study and the participants consented in writing, following detailed, informed consent procedures. In their previous analyses of this saturated data set, the authors did not consider whether/how Photovoice, a participatory visual method supported resilience processes, because the participants' accounts identified diverse risk factors as well as resilience-supporting mechanisms (see Adegoke 2015). For the purposes of this article, the authors conducted a secondary, inductive content analysis (Creswell, 2012) to investigate whether the photovoice perspective of the data actually contributed to resilience processes in HIV positive Yoruba adolescent girls' and if yes, what characterised these coping strategies.

\subsection{Procedure}

The data set for this article comprised 50 pages of text which was voluntarily generated by 5 resilient HIV positive Yoruba adolescent girls between the ages of 14-20 years and belong to the Yoruba ethnic group; (see Table 1 for a summary of participant details). As described in the previous study (see Adegoke, 2015) the girls were purposefully sampled, using social workers from NELA the research site as gatekeepers. The inclusion criteria hinged on (a) having attended HIV counselling and treatment centers, (b) evidence of positive adaptation and living a normal life as demonstrated by academic success or engagement in purposeful living such as gainful employment (c) evidence of social and emotional functioning (as used in precious resilience studies by Theron (2013); Ungar \& Liebenberg (2011). All nominated participants were asked to consider whether they thought of themselves as resilient and they agreed they did. All participants were HIV positive as evidenced from the NGO's office register of names. Some also endured not only the trauma of HIV but also stigmatisation and poverty (see Table 1) which predicted serious adversities to their development. The data set was generated by participants' response to the following broad and open ended questions: "Please share your story by relating the photograph you have chosen as reflecting how you adjusted well in the face of your HIV status." The first author who administered the questions also encouraged students retelling their stories with questions such as, "Why did you choose this picture over others? "What actually happened when you took this picture?" The role of the first author was more of an active listener than an interviewer. With their written permission, the students' narratives were audio recorded and transcribed while the preferred photographs were released to the first author.

\subsection{Data analysis}

The data analysis occurred in three phases specifically for this article. In the first phase we started with reading the data from the photovoice interview section all over again to trace categories of segments. We discarded any segments that did not relate to the participants resilience processes or does not correspond to photographs chosen by participants. The second phase witnessed the, analysis of the highlighted segments with the photographs to understand how the data impacted the participants' resilience process. To this end, we worked deductively (Creswell, 2009), using the lenses of Bourdieus' field theory (social capital), Piaget's cognitive theory (cognitive competence) and Erikson theory of identity formation (cultural identity and adherence) to determine how the pictures relate to the theoretical framework and the resilience theories (Dykes 2016, Theron 2013; Masten 2015). Thus, in the third phase, we coded segments from the data that characterized resilience processes/factors and risk factors To do so, we independently considered, and reconsidered, what relevant data segments (i.e., those referring to coping /protective factors from the data that impacted resilience processes and those that put them at risk. We coded these segments inductively, using labels that paraphrased what corresponds to each photograph (Creswell, 2012). Consequently, we worked through the data set and compared assigned codes. The assigning of codes was thoroughly done and mutually agreed upon and we named them themes. Then, we considered how quotes linked to the various labels assigned (i.e., themes) could be best connected to form categories that might shed light on the resilience pathways for participants. The categories were sorted under each theme. We presented our interpretation to seasoned education and resilience researchers at the faculty of education of the institution and used their responses to adjust our interpretation and enhance trustworthiness (Creswell, 2012). 


\section{Results}

Table 1 below summarizes each participant's context.

\begin{tabular}{|c|c|c|c|c|}
\hline $\begin{array}{l}\text { Participants' } \\
\text { pseudonym }\end{array}$ & Age & $\begin{array}{l}\text { Level of } \\
\text { education }\end{array}$ & $\begin{array}{l}\text { Present } \\
\text { Occupation }\end{array}$ & Circumstances placing participants at more risk \\
\hline Mary & 14 & $\begin{array}{l}\text { Senior } \\
\text { school-1 }\end{array}$ & Student & $\begin{array}{l}\text { Above poverty line: live with both parents: secure paternal } \\
\text { employment; literate father; protective and illiterate mother, } \\
\text { mother living with HIV and insecure employment. Live in fear of } \\
\text { disclosure of status. }\end{array}$ \\
\hline Modupe & 17 & $\begin{array}{l}\text { Senior } \\
\text { school-1 }\end{array}$ & Student & $\begin{array}{l}\text { Poverty; death of Father; lives with mother who is semi illiterate } \\
\text { but works as a seamstress; stigmatized and socially marginalized } \\
\text { by paternal family. }\end{array}$ \\
\hline Ajoke & 20 & $\begin{array}{l}\text { Dropped out } \\
\text { in Junior } \\
\text { school }-3\end{array}$ & $\begin{array}{l}\text { Employed as a } \\
\text { cleaner }\end{array}$ & $\begin{array}{l}\text { Poverty; secure paternal employment; very strict father, insecure } \\
\text { maternal employment; teenage pregnancy; lives with husband and } \\
\text { a child; husband equally HIV positive with insecure employment; } \\
\text { disrupted schooling; both stigmatized and socially marginalized by } \\
\text { father and neighbours. }\end{array}$ \\
\hline Adijat & 20 & $\begin{array}{l}\text { No } \\
\text { education at } \\
\text { all }\end{array}$ & $\begin{array}{l}\text { Petty trader, } \\
\text { (Hawker) }\end{array}$ & $\begin{array}{l}\text { Poverty; diseased father; aged illiterate mother who is } \\
\text { unemployed; illiteracy; teenage pregnancy; living with husband } \\
\text { and a child; stigmatized and traumatized by husband who is HIV } \\
\text { negative. }\end{array}$ \\
\hline Cecilia & 20 & $\begin{array}{l}\text { Dropped out } \\
\text { in Senior } \\
\text { school-1 }\end{array}$ & $\begin{array}{l}\text { Secure } \\
\text { personal } \\
\text { business }\end{array}$ & $\begin{array}{l}\text { Above poverty line; lives with husband who is equally HIV } \\
\text { positive and with secure employment; disrupted schooling illiterate } \\
\text { parents; parents and neighbours unaware of her HIV status for fear } \\
\text { of stigmatization; live in fear of disclosure of status; teenage } \\
\text { pregnancy; has a child. }\end{array}$ \\
\hline
\end{tabular}


In this section we present the results of the study from the photovoice technique with the narratives.

\subsection{Case 1}

\subsubsection{Participant Mary}

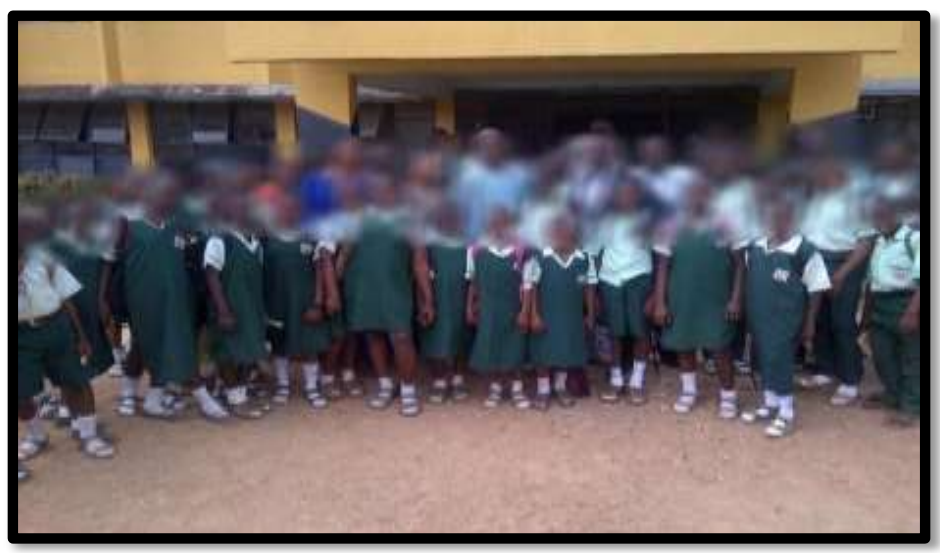

Figure 1: Mary’s photographs reflecting her resilience

Narrative: Mary brought two photographs. She took one photograph with her mother and another one in the company of other students and teachers in her school. When asked to choose which one reflected her resilience, she preferred the school photograph. According to her, education is the only weapon with which she can further her cause by becoming a journalist, airing the voices of HIV positive adolescent girls.

- I like school and want to be a journalist to warn other girls to desist from boys so that they do not destroy their lives. I will collect information from HIV positive girls and write it in the newspaper.

She therefore finds solace in schooling and being close to her schoolmates, even though her status is not known to them. 


\subsection{Case 2}

\subsubsection{Participant Modupe}
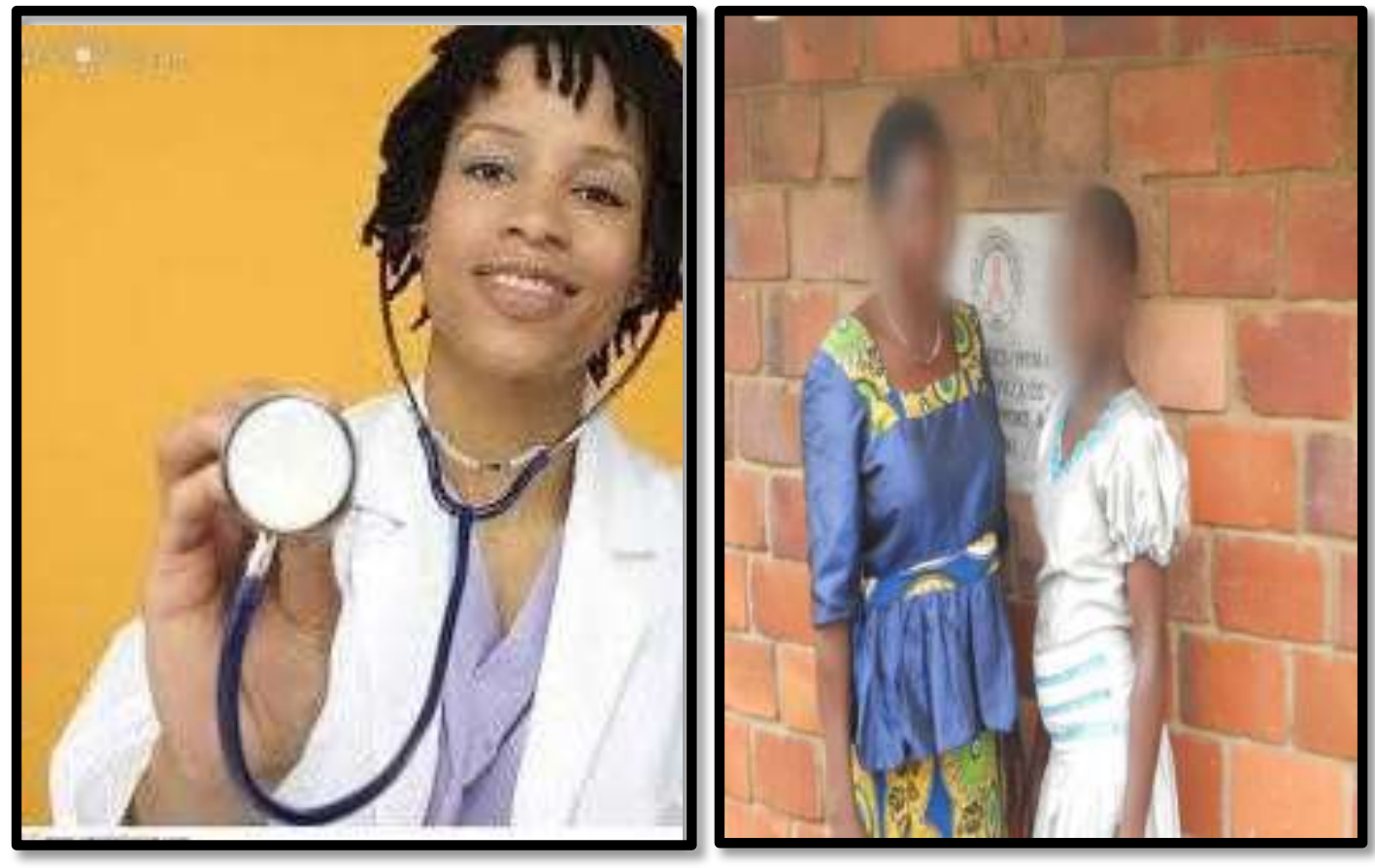

Figure 2: Modupe's photographs reflecting her resilience

Narrative: Modupe presented these two photographs and when prompted to choose the better, she insisted both were reflections of her resilience. The first picture is that of a lady medical doctor that she pasted in her room as she hopes to become one in future in order to help fight HIV/AIDS.

- I want to be a medical doctor and I want to study medicine. Am in Science class. So this picture reminds me of it that I can achieve that goal.

- If you are successful no one will look down on you.

According to her she has been able to survive her traumatic experiences due to her mother's unflinching support.

- I don't have anyone except my mother. I don't have any support. Only my mother supports me.

The photograph gives her the impetus to forge ahead in life. 


\subsection{Case 3}

\subsubsection{Participant Ajoke}

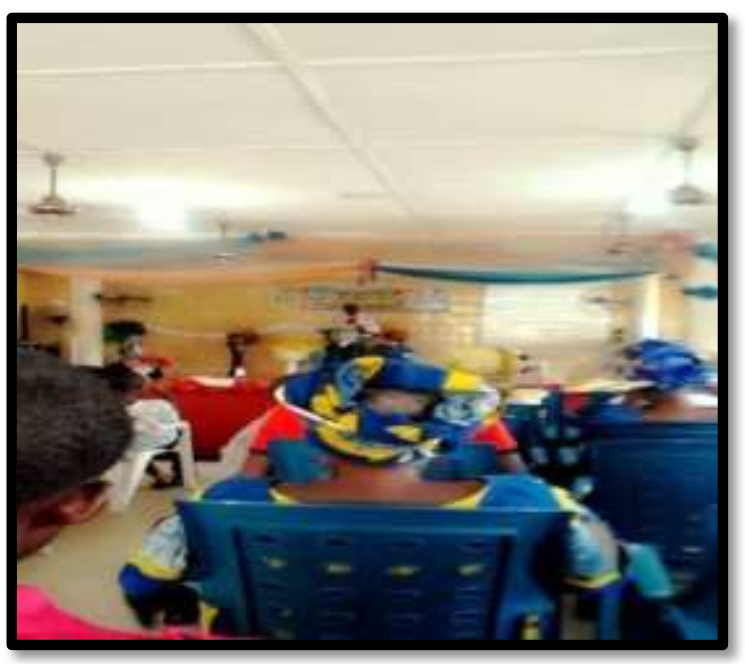

Figure 3: Ajoke's photograph reflecting her resilience

Narrative: Ajoke took two pictures but preferred that of her church. She mentioned that she disclosed her identity only to the pastor of her church so that he could pray for her. The pastor has instilled confidence into her that one day she would receive spiritual healing and be cleansed of her disease.

- Only the pastor knows and he used to pray for us and he told us God will do a miracle.

According to her the pastor conducts a series of prayer sessions, fasts and private counselling for her and her husband. The pastor happens to be the only person who sympathises with them and would not discriminate against them but would rather keep their status secret from others. 


\subsection{Case 4}

\subsubsection{Participant Adijat}

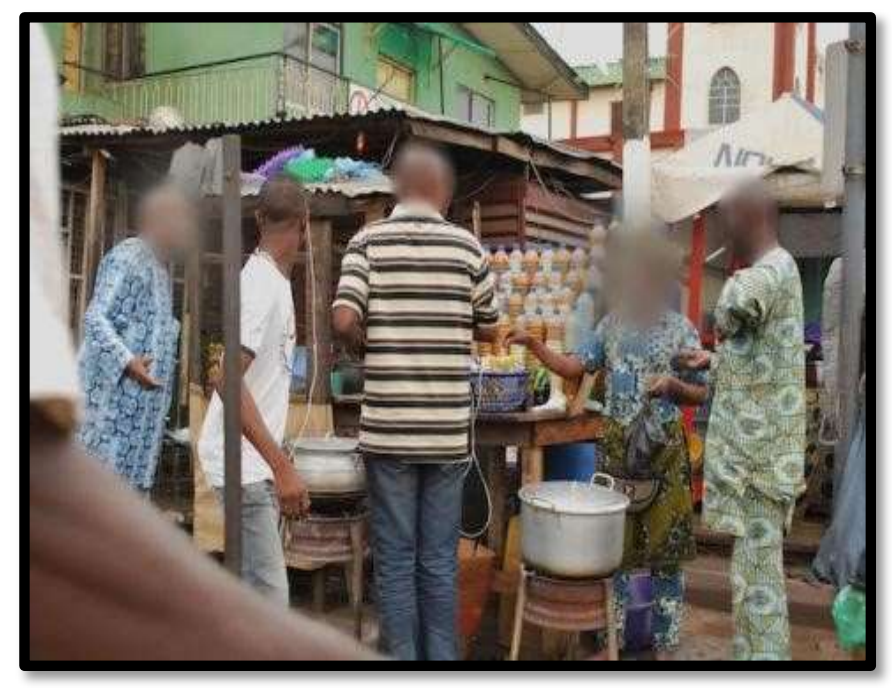

Figure 4: Aditjat's photograph reflecting her resilience

Narrative: Adijat came with the photograph of her trade where she receives financial support. She sells local drinks (kunu) at a taxi rank (Motor Park). She sometimes hawks (displaying goods by walking round the streets) the drink for maximum profit.

- I set up this kunu business to support my mum and only child.

- And I know that one day this HIV will have a cure.

Even though she laments her inability to attend school, she has been able to secure friends among her fellow women within the trade who are also HIV-positive. Her world revolves round the people she meets daily on the streets as she has no one to discuss her emotional experiences with at home.

- No education and no one to help me were responsible for my early marriage and having a child. Am exposed to different kinds of people here where I sell my stuff and am very close to them, especially those who are HIV positive like me. 


\subsection{Case 5}

\subsubsection{Participant Cecilia}

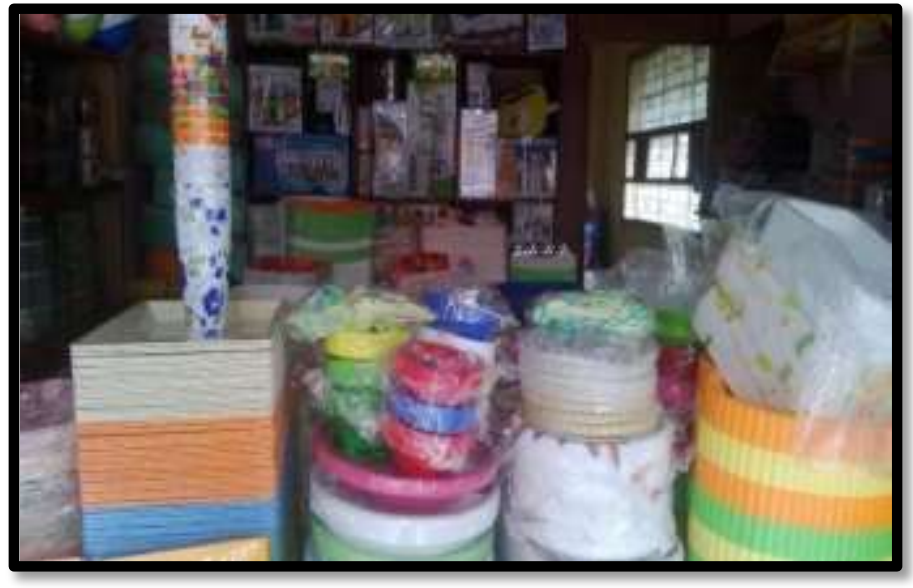

Figure 5: Cecilia's photograph reflecting her resilience

Narrative: In her narrative Cecilia explained that nobody knew anything about her HIV status because she was able to seek both medical and financial help and settle down to a flourishing business selling kitchen and house utensils.

- Am trading in kitchen utensils. My husband empowered me because he has been into the business before me. From here we get money to eat good food that makes me happy and strong.

Her experience made her start advising her friends about HIV/AIDS. She owns a shop and controls her business. This has been a source of her resilience and comfort. 


\section{Discussion}

Below is the synthesis of the data. The themes reflect resilience theories and the categories are supported data indicating the depth of each theme.

Table 2: Themes and Categories

Adapted from Dykes (2016)

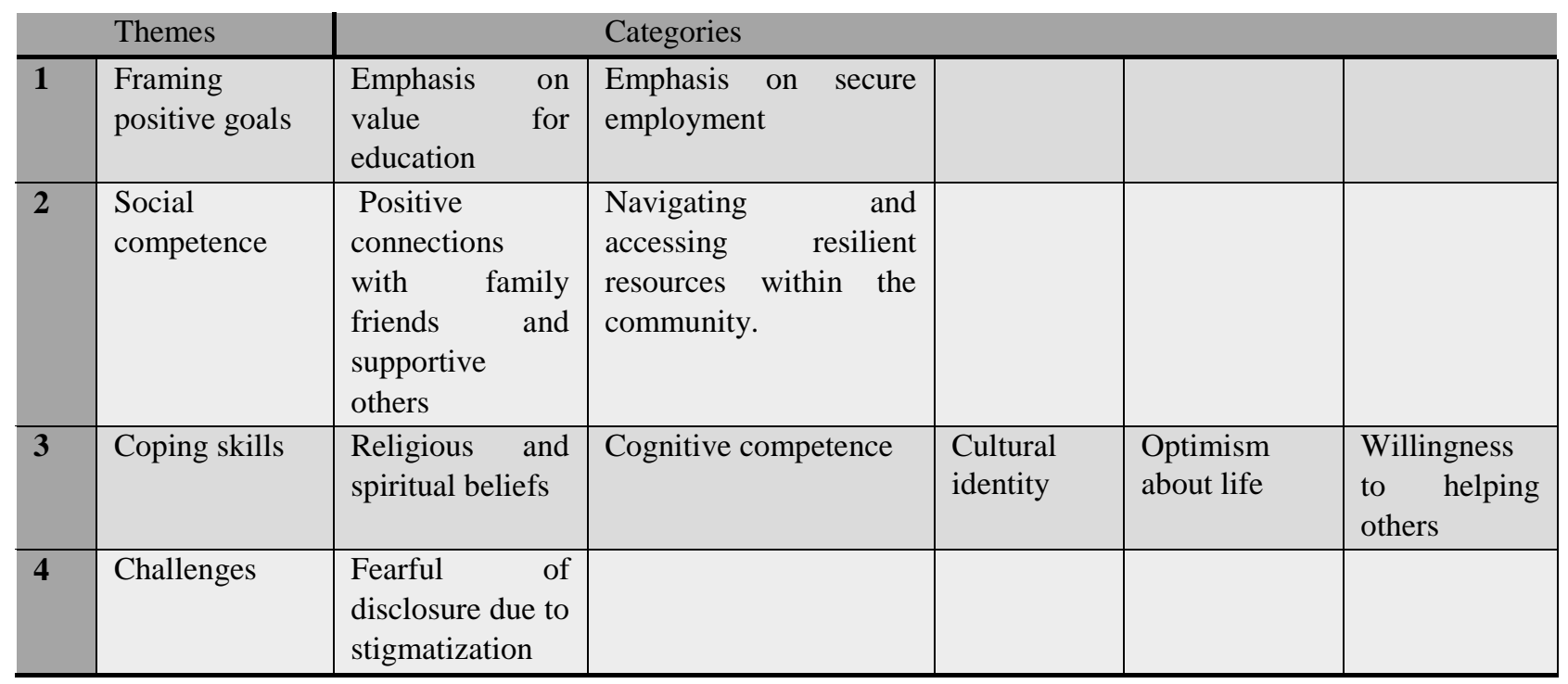

Table 2 clarifies the four themes and ten categories that emerged from the synthesised data.

\subsection{Framing positive goals}

A common feature in resilience among HIV positive adolescents is their continual appreciation for education and gainful employment which characterized the two categories reflected in their photographs. Motivation to succeed, going to school and learning are standards of judging progress as well as prospects in development (Masten 2015). Positive values such as education a secure employment will enhance the individual's self-esteem and purpose.

\subsubsection{Emphasis on value for education}

All participants value education and want to advance further in education. Mary and Modupe believe becoming resilient lies very much in their furthering education. Hence they took photographs depicting education. They also enjoy being in school even though they keep their HIV status secret from others. Ajoke in particular could not hide her sadness as she said early pregnancy triggered her dropping out of school. Adijat, on the other hand, never went to school and believes this was why she met the misfortune of contracting HIV and unemployment. Ajoke, Adijat and Cecilia wished they could get help to further their education.

\subsubsection{Emphasis on secure employment}

Participants photographs and interview highlighted dedication to hard work either at school or while employed. To them employment is empowerment and they all share one goal in life and this is to thrive in their chosen endeavours. They emphasised that hardwork will help in achieving their aims of securing good employment. Adijat and Cecilia confirmed that their businesses are thriving and hence they chose the photograph of their businesses. Modupe and Mary on the other hand dream to become a doctor and a journalist respectively. Adijat, Ajoke and 
Cecilia are working hard and dedicated to their work to prove people wrong that HIV-positive people are weaklings or too vulnerable to work.

\subsection{Social competence}

Participants exhibited social competence by networking with people around them to deal with their hardships. Social competence is the foundation upon which expectations for future interactions with others are built and the concept of social competence encompasses constructs such as social skills, social communication and interpersonal communication (Semrud-Clikeman, 2007). Participants' photographs and interview revealed these traits in two categories.

\subsubsection{Positive connections with family friends and supportive others}

All participants maintain close relationships with family members, friends and the social workers in the NELA organisation to resource for help either emotionally (counselling) or materially (food, housing, medical care). Mary is very active in her class where she socialises with friends as shown from her photograph. She is also close to her mother who protectively chaperons her everywhere. Modupe revealed that her mother vowed to make sure she becomes resilient by supplying all her needs and brings her to the centre for treatment and counselling hence she took a photograph with her mother. Adijat took photographs with her customers at the taxi rank where she sells her local drinks. Ajoke is happy socializing with her church members particularly the pastor of the church and Cecilia confirmed she enjoys counselling people around her about HIV.

\subsubsection{Navigating and accessing resilient resources within the community.}

The fact that participants were able to decide to attend health and counselling centers indicates they possess social competence to navigate for their resilience. Ajoke decided to attend church to navigate emotional and psychological resilience. Adijat for instance disclosed that she has been involved in different types of businesses with friends and joined many associations in order to make ends meet. She attracts customers to her present business by being extremely friendly even though the customers are not aware of her status. These traits are evidenced in their photographs. Participants possess 'the ability to steer towards resilient resources' (Masten \& Wrights, 2010; Theron 2013).

\subsection{Coping skills}

Coping in adolescence is distinguished by its focus on how they deal with actual stressors in real-life context. Coping is defined as "regulation under stress" with established links to the development of emotional, intentional, and behavioral self-regulation factors (Skinner \& Zimmer Gembek (2007). Participants exhibited different ways of coping with their adversities which are in five categories.

\subsubsection{Religious and spiritual beliefs}

Participants draw on their beliefs and values concerning spirituality and religion to cope with stressful experiences. All participants believe in God's intervention in curing the disease totally in the near future. Mary and Modupe believe that with their parents and God's supports they will excel in life while they, on their part, are working hard academically in school. Ajoke believes only God can heal her and attends church regularly where her pastor prays for her hence she chose a picture of her church. Adijat is confident she will become successful despite her being an illiterate as she relies on God. Study results show that religion is a significant conduit for meaningmaking following trauma and loss (called spiritual coping) that is associated with healthy outcomes (Dykes 2016, Park, 2005).

\subsubsection{Cognitive competence}

The girls have managed to achieve emotional control as a process or journey to self-discovery. The literature discussed has explicated the key aspects that appropriately focus on the self. Piaget (1932/52) explained that the 
adolescent is capable of higher order of reasoning to deal with his/her difficulties. Therefore self-awareness and mindfulness as well as problem solving skills are significant drivers on this journey. By accepting their status and ready to move forward in life is a positive indicator of resilience. Throughout the interview session participants controlled their emotions and rather look forward to a better life.

\subsubsection{Cultural identity}

Participants' resilience strategies reflected Yoruba cultural beliefs which place high value on education, hard work, marriage, dressing, spiritual and religious beliefs. The girls' photographs and narratives lend credence to these assertions. This aligns with Ericson's theory (1959/68) that adolescence is the period of identity formation. It also directs attention to better understanding of the culture and context of adolescents and how this informs service uptake and resilience processes.

\subsubsection{Optimism about life}

The girls' photographs portrayed optimism and that the girls exhibited positive outcomes in the face of their adversities. The ability to become resilient despite all odds is a personal trait that has helped them to sustain their well-being. Mary and Modupe revealed that they were happy and satisfied with their education and parental support. Cecilia was also optimistic about her spouse's support and trade, which influenced her bouncing back to normal life. Adijat felt secure with the social network with people around her as her source of resilience pathway. They all believe in God's intervention and subsequent protection from untimely death as a result of their status. It is believed that the evaluation of happiness depends mostly on one's judgments.

\subsubsection{Willingness to help others}

Participants photographs depicted they are willing to help others by developing empathy and pro-social behaviour. For instance, Mary, Modupe and Cecilia are willing to help adolescent girls receive information about the disease and conquer its effects. To this effect Mary wanted to become a journalist, Modupe a doctor and Cecilia offer advice to her neighbours both at work and at home to go for HIV tests to be sure of their HIV status. Adijat is into her new business in order to take care of her mother and child.

\subsection{Challenges}

Participants were not without personal challenges even though they claim to be resilient. Resilience occurs when there is persistent adversity or hardship that may disrupt normal development (Masten 2014). Nevertheless, participants' resilient strategies were able to cushion the negative effects of their challenges. The irksome personal challenges expressed by participants aside those discussed in Table 1 are common to all and discussed under one category.

\subsubsection{Fear of disclosure of status}

Due to fear of stigmatisation and discrimination, all participants are afraid of disclosing their status; hence they maintain close relationships only with those with the same HIV status, or with their parents and spouses. To them non-disclosure facilitates their resilience and they would rather keep their status to themselves and seek help through organisations and other social networks. HIV is a dreaded disease in society and fortunately for those who have it and are already coping well, it is easy to hide their status as long as they show no signs of the disease.

\section{Recommendations}

This study makes strong recommendations that could assist in alleviating the plight of girls who find themselves in similar conditions. Since the federal, state and local governments drive the development and implementation of relevant policies and programmes in Nigeria it is recommended that:

The Federal Legislative Council and the States Houses of Assemblies should give legislative backing to provide social grants for HIV-positive adolescent girls while the ministries of youth, social development, local and community developments should collaboratively put in place procedures that will allow these girls to access such grants. HIV positive adolescent girls need support to enable them to re-enter to normal life. They should also 
collaborate with programme officers from NGOs (Non-governmental organisations) and CBOs (Community Based Organisations) to reach out-of-school youths with comprehensive and functional FLHE, using community-based platforms. The motivation for this is the pervasive low level of comprehensive knowledge about HIV, poor sexual health-seeking behaviours among adolescents, which negatively affect their resilience building process in Nigeria a well as reduce stigma associated with the disease.

\subsection{Limitations of the study}

The study was conducted with participants from a specific culture and therefore the findings are unique to the context of this setting and can therefore not be generalised to other contexts. This is not unusual because the importance of context is emphasised in qualitative research studies. The findings can provide insight into adolescence resilience pathways (particularly in Sub-Saharan Africa) where adolescent girls' profiles are similar.

Another limitation is that there could be other revelations about participants which what was photographed has denied and subsequently not discussed in the Photo voice interview, which are equally as important to consider as the findings. In this case, interviews were purposefully structured to explore participants' perspectives beyond just what was photographed through a general line of questioning that created opportunities to comment on other important issues.

\section{Conclusion}

The girls in this study come from predominantly deprived settings and face diverse adverse conditions which could hinder their resilience. Notwithstanding, the photographs displayed demonstrated they have the capacity to overcome their challenges and remain resilient. Photo voice has been used as a flexible tool in this study to elucidate discussion among participants that has revealed outcomes that are important to improve both adolescents and communities' health (Catalanu \& Minkler 2010). This research implies that HIV positive adolescent girls are no longer passive victims who sit and wait for help, but are competent "social actors" with "social capital" (Bourdieu , 1989) who actively cope with difficult social circumstances through their coping skills, social network of family and friends, cognitive skills and resourcefulness.

\section{References}

Adegoke, C.O. (2015). Key factors in enhancing the resilience of HIV positive adolescent girls in Nigeria, $\mathrm{PhD}$ Thesis, University of Pretoria, Pretoria. South Africa.

Aggleton, P., Ball, A., \& Mane, P. (2000). Young people, sexuality and relationships. Sexual and Relationship Therapy, 15(3), 213-220.

Ajala, S. A. (2007). HIV/AIDS in Yoruba perspectives: A conceptual discourse. Journal of Social Science 14(3), 235-241.

Arnett, J.J. (2000). Emerging adulthood: a theory of development from the late teens through the twenties. American Psychologists, 55(5), 469-480.

Bourdieu, P. (1989). Social space and symbolic power. Sociological Theory, 7(1), 14-25.

Bourdieu, P. (1990). The logic of practice. Cambridge: Polity.

Bourdieu, P. (2004). The forms of capital. In S. Ball (Ed.), The Routledge Falmer reader in sociology of education. London: Routledge Falmer, pp.15-29. 
Cluver, L. D., Gardner, F., \& Operario, D. (2008). Effects of stigma on the mental health of adolescents orphaned by AIDS. Journal of Adolescent Health, 42(4), 410-417.

Catalani, C.,\& Minkler, M. (2010). "Photo voice: A review of the literature in health and public health." Health Education \& Behavior 37.3 (2010), 424-451.

Creswell, J.W. (2009). Research design. Qualitative, quantitative and mixed methods approaches. Thousand Oaks, CA: Sage.

Creswell, J.W. (2012). Educational research. Planning, conducting, and evaluating qualitative research (4th ed.). Boston, MA: Pearson.

De Santis, J. P., \& Barroso, S. (2011). Living in silence: A grounded study of vulnerability in the context of HIV infection. Issues in Mental Health Nursing, 32, 345-354.

Dykes, G. (2016). Coping, resilience and post-traumatic growth: adverse childhood experiences and social work students. The Social Work Practitioner-Researcher, 28(1), 18-35.

Erikson, E.H. (1959). Identity and the life cycle. Psychological Issues, 1, 1-171.

Erikson, E.H. (1968a). Identity: Youth and crisis. New York: Norton.

Federal Ministry of Health, NACA. (2001). HIV/AIDS Emergency Action Plan (HEAP), sections 12:http://www.nigeria-aids.org/pdf/heap.pdf.

Ferreira, R., \& Ebersohn, L. (2012). Partnering for resilience. Hatfield, Pretoria: Van Schaik.

Henley, C., McAlpine, R., Mueller, M. \& Vetter, S. (2010). A survey of street children in Northern Tanzania: How abuse or support factors may influence migration to the street. Community Mental Health Journal, 46(1), 26-32.

Jacobs, J.E. \& Klaczynski, P.A. (Eds.) (2005). The development of judgment and decision making in children and adolescents. Mahwah, NJ: Erlbaum.

Kamper, G. D., \& Steyn, M. G. (2011).Black students' perspectives on learning assets at a historically white university.Journal of Asian an African Studies, 46(3), 287-292.

Liebenberg, L., \& Ungar, M. (2009). Introduction: The challenges in researching resilience. In L.Liebenberg \& M. Ungar (Eds.), Researching resilience. Toronto: University of Toronto Press, pp. 3-25.

Masten, A.S. (2014). Global perspectives on resilience in children and youth. Child Development, 85(1), 6-20, http://dx.doi.org/10.1111/cdev.12205.

Masten, A.S., Best, K.M., \& Garmezy, N. (1990). Resilience and development: Contributions from the study of children who overcome adversity. Development and Psychopathology, 2(4), 425-444.

Masten, A.S. (2015) Resilience in Development. Early Childhood as a Window of Opportunity. University of Minnesota.

http://healthpolicy.unm.edu/sites/default/files/Masten\%20UNM\%20conference\%20April\%202015\%20Final.pdf.

Masten, A.S., \& Wright, M.O. (2010). Resilience over the lifespan: Developmental perspectives on resistance, recovery and transformation. In J.W. Reich, A.J. Zautra, \& J.S. Hall (Eds.), Handbook of adult resilience (pp. 213-237). New York, NY: Guilford.

NPC (2006). http://www.population.gov.ng/ 
Oladepo, O., \& Fayemi, M. M. (2011).Perceptions about sexual abstinence and knowledge of HIV/AIDS prevention among in-school adolescents in a western Nigerian city.BMC. Public Health, 11, 304-330.

Olivier, T., Wood, L., \& De Lange, N. (2009). Picturing hope: In the face of poverty as seen through the eyes of teachers. Cape Town: Juta.

Park, C. (2005). "Religion as a Meaning-making Framework in Coping with Life Stress" Journal of Social Issues 61(4):707-729.

Piaget, J. (1932). The moral judgment of the child. London: Paladin.

Piaget, J. (1952). The origin of intelligence in children. New York: International University Press.

Semrud-Clikeman M. (2007) Social Competence in Children. Springer Science + Business Media: New York,

Skinner E. A. \& Zimmer-Gembeck M. J. (2007). The development of coping. Annu. Rev. Psychol. 58:119-44

Theron, L.C. (2013). Black students' recollections of pathways to resilience: Lessons for school psychologists. School Psychology International, 1-13.

Theron, L., Cameron, C.A., Didkowsky,N., Lau, C., Liebenberg, L., \& Ungar, M.(2011).A "day in the lives" of four resilient youths: Cultural roots of resilience. Youth \& Society. DOI: 0044118X11402853

UNAIDS. (2012). Report on the global AIDS epidemic: at http://www.unaids.org/en/resources/campaigns/20121120_globalreport2012/globalreport. Accessed 14 November 2014.

Ungar, M. (2011). The social ecology of resilience: Addressing contextual and cultural ambiguity of a nascent construct. American Journal of Orthopsychiatry, 81, 1-17.

Ungar, M., \& Liebenberg, L. (2011). Assessing resilience across cultures using mixed methods: Construction of the Child and Youth Resilience Measure. Journal of Mixed Methods Research, 5(2), 126-149, http://dx.doi.org/10.1177/1558689811400607.

Ungar, M. (2008). Resilience across cultures. British Journal of Social Work, 2, 218-35. Press.

UNICEF. (2008). HIV/AIDS in Nigeria: A report: http//www.unicef.org. Accessed 14 November 2014.

Van Rensburg, A.C., Theron, L.C., Rothmann, S., \& Kitching, A. (2013). The relationship between services and resilience: A study of Sesotho-speaking youths. The Social Work Practitioner-Researcher, 25(3), 286-308.

Wright, M.O.D. \& Masten, A. S. (2015). Pathways to resilience in context. In Youth resilience and culture (Vol. 11), Cross-cultural advancements in positive psychology, Springer, pp. 3-22.

Wang, C., \& Burris, M. A. (1997). Photovoice: Concept, methodology, and use for participatory needs assessment. Health Education \& Behavior, 24(3), 369-387.

Wang, C. C. (2006). Youth participation in photovoice as a strategy for community change. Journal of community practice, 14(1-2), 147-161. 